
6

\title{
Adjuvant external beam radiotherapy following enucleation of eyes with extraocular extension from uveal melanoma
}

Kelsey A. Roelofs MD FRCSC ${ }^{1}$

Victoria M.L. Cohen MA, MB BChir, FRCOphth ${ }^{1,2}$

Mandeep Sagoo MB, PhD, FRCOphth ${ }^{1,2}$

P. Nicholas Plowman, FRCR ${ }^{3}$

Guy S Negretti MB, BChir, FRCOphth ${ }^{1}$

Roderick O’Day MBBS, FRANZCO ${ }^{1 .}$

Gordon Hay, MBBS ${ }^{1,2}$

Amit K. Arora MBBS, MRCOphth 1,2

Bertil Damato MD, PhD, FRCOphth ${ }^{1}$

${ }^{1}$ Ocular Oncology Service, Moorfields Eye Hospital, London, United Kingdom, UK

${ }^{2}$ NIHR Biomedical Research Centre for Ophthalmology at Moorfields Eye Hospital and University College London Institute of Ophthalmology, UK

${ }^{3}$ Department of Radiation Oncology, St. Bartholomew's Hospital, London, UK

${ }^{4}$ Nuffield Laboratory of Ophthalmology, Nuffield Department of Clinical Neurosciences, University of Oxford, UK

Abstract Word Count: 284 words

Manuscript Word Count: 2401 words

Running title:

Management of extraocular extension from uveal melanoma

Corresponding Author:

Professor Bertil Damato, MD, PhD, FRCOphth Moorfields Eye Hospital NHS Foundation Trust, 162 City Road, London, EC1V 2PD

Tel: 02072533411

Email: bertil.damato@nhs.net

No financial support was received for this research. None of the authors have any financial disclosures or conflicts of interest to declare. This manuscript has not previously been submitted for publication and has not been presented at a meeting.

The research supported by the National Institute for Health Research (NIHR) Biomedical Research Centre based at Moorfields Eye Hospital NHS Foundation Trust and UCL Institute of Ophthalmology. The views expressed are those of the author(s) and not necessarily those of the NHS, the NIHR or the Department of Health.

Keywords: extraocular extension, uveal melanoma, external beam radiotherapy, enucleation 


\section{PRÉCIS}

48

49 In 51 patients with extraocular extension of uveal melanoma undergoing enucleation, none

50 developed clinically apparent orbital recurrence and no difference in all-cause mortality

51 between observation versus adjuvant external beam radiotherapy was found.

52 


\section{ABSTRACT}

55 Purpose: To report local disease control and all-cause mortality in patients with extraocular extension (EOE) of uveal melanoma (UM) undergoing enucleation followed by observation

57 or external beam radiotherapy (EBRT).

58 Methods: Charts of patients enucleated between January $1^{\text {st }}, 1997$ and December $31^{\text {st }}, 2019$, with histopathological evidence of EOE of UM were reviewed.

Results: The cohort comprised 51 patients with a mean age of $67 \pm 15$ years, $22(43 \%)$ of whom underwent adjuvant post-enucleation EBRT. Risk factors for metastasis included presence of epithelioid cells $(29 / 45 ; 88 \%)$, closed loops $(20 / 43 ; 47 \%)$, monosomy $3(16 / 25$; $64 \%)$ and gain of $8 \mathrm{q}(20 / 22 ; 91 \%)$. Patients undergoing EBRT had more extensive EOE (median: $5.1 \mathrm{~mm}$ vs $2.6 \mathrm{~mm}, \mathrm{p}=0.008$ ) and surgical excision was less likely to be histologically complete $(2 / 20 ; 10 \%$ vs $14 / 25 ; 56 \%, p=0.002)$. Local side effects following EBRT were seen in $64 \%(14 / 22)$. At latest follow up, 59\% of patients $(30 / 51)$ were alive, with a median follow-up of 1.8 years [IQR 2.9, range $0.1-6.5]$. By Kaplan Meier survival analysis, the 5- and 10- year overall survival rates were $56 \%$ and $12 \%$ respectively. There was no difference in all-cause mortality between those receiving adjuvant EBRT and those who were observed (log rank, $\mathrm{p}=0.273)$. No cases of orbital recurrence were documented. undergoing enucleation can be safely observed, without adjuvant EBRT. Multi-center studies are required to better assess the role of EBRT when EOE is more extensive. 
77

78

79

80

81

82

83

84

85

86

87

88

89

90

91

92

93

94

95

96

97

98

99

INTRODUCTION

7

8

9

$(\mathrm{UM})^{1-4}$ and approximately $13 \%$ of cases undergoing enucleation. ${ }^{5-8}$ The $8^{\text {th }}$ edition of the

American Joint Committee on Cancer (AJCC) includes EOE in its models for predicting

metastatic death, categorizing any extraocular nodules according to whether they exceed 5

$\mathrm{mm}$ in diameter.

The treatment for UM with EOE has been debated for several decades. In 1964,

Hogan recommended enucleation with limited exenteration followed by prophylactic

radiotherapy. ${ }^{9}$ In 1977, Shammas and Blodi advocated for exenteration in all cases of EOE from UM, regardless of the extent of orbital involvment. ${ }^{10}$ In 1980, Affeldt et al reported that exenteration did not improve survival ${ }^{5}$ and in 1985 , Kersten et al found long-term survival to be the same whether or not exenteration was performed, except in patients with surgically transected or non-encapsulated EOE. ${ }^{11}$ In an effort to avoid disfiguring surgery, in 1990, Hykin et al. reported their positive experience using external beam radiotherapy (EBRT) as an alternative to exenteration in preventing orbital tumour recurrence. ${ }^{12}$ However, EBRT can cause significant morbidity, such as socket contracture precluding prosthesis wear in upwards of $40 \%$ of patients. ${ }^{13}$

Although the use of post-operative orbital radiotherapy is often mentioned anecdotally, to the best of our knowledge, only a handful of case-series have been reported, all of which had relatively small numbers of patients. ${ }^{12-15}$ Since Hykin et al reported outcomes from our institution in $1990,{ }^{12}$ we have noticed very little local relapse and therefore, the authors practice has evolved over time to giving adjuvant radiotherapy primarily in cases of large or incompletely resected EOE. The purpose of the present study 
100

101

102

103

104

105

106

107

108

109

110

111

112

113

114

115

was to improve evidence-based management of patients with EOE from UM undergoing enucleation.

\section{METHODS}

This retrospective study was approved by the Moorfields Eye Hospital clinical audit department (No; 521) and was conducted in accordance with the Declaration of Helsinki. An electronic repository was searched for the key words: "extra-scleral or extraocular extension" and "uveal melanoma" occurring in clinical letters dictated between January $1^{\text {st }}, 1997$ and December $31^{\text {st }}$, 2019. Patient files were reviewed for demographic details, histopathological findings, cytogenetic results, details regarding EBRT, evidence of local tumour recurrence, metastasis and death. The term 'pseudo-encapsulation' was used to describe cases in which the entire extra-ocular nodule of tumour was covered by at least a thin layer normal tissue, consisting of Tenons for posteriorly located lesions and conjunctiva $+/$ - Tenons for anteriorly located tumours. Those undergoing EBRT received 50 Gy in 20 fractions with 6MV x-rays, typically administered over 4 weeks, as this was the protocol reported by Hykin et al. from our institution in $1990 .{ }^{15}$ Patients who did not have a date of death listed in the electronic medical record, and who had not been seen in clinic within six months of the study close were contacted via telephone to determine their vital status and exclude orbital recurrence.

Conventional descriptive statistics were employed and the data presented as mean \pm standard deviation (SD) when normally distributed or as median [interquartile range and range], if not. All variables were assessed for normality using the Shapiro-Wilk and Kolmogorov-Smirnov tests. The students t-test was used when continuous variables were normally distributed and the variance between groups was again checked using Levene's test for quality of variances. When not normally distributed, the Mann-Whitney U test was 
124

125

126

127

128

129

130

131

132

133

134

135

136

137

138

139

140

141

142

143

144

145

146

147

148

employed. Differences in categorical variables were assessed using Fisher's exact test with the Freeman-Halton extension. A p-value of $<0.05$ was considered statistically significant. Kaplan-Meier survival estimate curves were used to predict all-cause mortality. All data was analysed using commercially available software (Stata Statistical Software. StataCorp LP and SPSS ${ }^{\circ}$; IBM Corporation, Armonk, NY, USA).

\section{RESULTS}

A total of 51 patients with a mean age of $67 \pm 15$ years who underwent enucleation with histopathological evidence of EOE from UM were included. There were slightly more males $(59 \%)$ than females. Most patients $(39 / 51 ; 77 \%)$ underwent enucleation as primary treatment. Twelve patients (24\%) were enucleated because of failed plaque brachytherapy $(\mathrm{N}=10)$, plaque and proton beam radiotherapy $(\mathrm{N}=1)$; and EBRT (as the lesion was initially diagnosed as choroidal metastasis $)(\mathrm{N}=1)$. The mean LBD and tumour thickness were $18.5 \pm$ $6.0 \mathrm{~mm}$ and $9.2 \pm 4.2 \mathrm{~mm}$, respectively. Fifty-five percent of the tumours included in this study were therefore AJCC T4 (28/51; 55\% [T4c: 4 cases, T4d: 15 cases, T4e: 9 cases]). Similarly, $18 \%(9 / 51)$ were stage IIIA, 20\% (10/51) were stage IIIB and 47\% (24/51) were stage IIIC.

On histopathology, mixed/epithelioid cell type was the most common cytomorphology $(29 / 45 ; 88 \%)$. In approximately half of the cases, mitotic count per $\mathrm{mm}^{2}$ was $>2(29 / 51 ; 57 \%)$ and closed loops were identified $(20 / 43 ; 47 \%)$. Cytogenetic testing using fluorescence in situ hybridization (FISH) was routinely performed only after 2010 and omitted after secondary enucleation because of concerns that genetic modification might occur following radiotherapy of the tumour. ${ }^{16}$ Therefore, data on chromosomal aberrations were available for 25 cases. Monosomy 3 was found in 64\% (16/25) and gains in 8q were demonstrated in almost all cases tested $(20 / 22 ; 91 \%)$. The median size of EOE was $5.0 \mathrm{~mm}$ [IQR: 4, Range: 1 - 11]. Excision of EOE was histologically considered complete in 36\% 
149 (16/45) and the nodule was reported to be completely enclosed within a pseudo-capsule of overlying normal tissue in $29 \%$ (10/35).

152 patients undergoing EBRT $(4 / 22 ; 18 \%)$ had failed prior radiotherapy as primary treatment

153 (plaque brachytherapy in 3 patients; plaque and proton beam radiotherapy in one patient).

154 Radiotherapy was administered as per the protocol employed in the London Ocular Oncology

155 Service (i.e., 50 Gy in 20 fractions with 6MV x-rays, typically administered over 4 weeks). ${ }^{15}$

156 There was no difference in mean age $(p=0.334)$, intraocular tumour LBD $(p=0.779)$ or

157 thickness $(\mathrm{p}=0.374)$ between patients undergoing EBRT compared to those who were

158 observed. With respect to histopathologic features, eyes undergoing EBRT were more likely 159 to have larger EOE (median $=5.1 \mathrm{~mm}$ versus $2.6 \mathrm{~mm} ; \mathrm{p}=0.008$ ) and less likely to have complete surgical excision of EOE $(21 \%$ versus $56 \% ; p=0.002)$. There were no statistically significant differences in incidence of closed loops $(p=0.547)$, cell type $(p=0244)$, mitotic count $(p=0.731)$, pseudo-encapsulation of EOE $(p=0.098)$, monosomy $3(p=0.098)$ or gain of $8 \mathrm{q}(\mathrm{p}=0.238)$ between the intraocular tumours of the two groups. (Table 1$)$

At latest follow up, $59 \%$ of patients $(30 / 51)$ were alive and these patients were followed for a median of 1.8 years [IQR 2.9, range $0.1-6.5$ years]. By Kaplan Meier survival analysis, the 5- and 10- year overall survival rates were $56 \%$ and $12 \%$, respectively. (Figure 1) There was no statically significant difference in survival between those receiving

168 EBRT compared to those who were observed $(\mathrm{p}=0.273)$. (Figure 2) One patient had undergone plaque brachytherapy 4 years prior to enucleation for local recurrence. This patient developed systemic metastatic disease within 3 weeks of enucleation; therefore, it is possible that the orbital component of this tumour was a local metastasis, rather than a direct extension of the intraocular lesion. This patient was still alive at the study close, 8 months

173 post-enucleation. 
There were no clinically apparent orbital recurrences in any patient included in this

175

176

177

178

179

180

181

182

183

184

185

186

187

188

189

190

191

192

193

194

195

196

197

study. Fourteen of the 22 patients $(64 \%)$ receiving EBRT had radiotherapy-related sideeffects, including socket contracture (4 patients), persistent inflammation of the eyelids and socket ( 8 patients), implant exposure (1 patient) and ongoing socket discomfort necessitating removal of the implant (1 patient). Of the four patients undergoing EBRT who had previously been treated with either plaque brachytherapy and/or proton beam radiotherapy, there were no significant complications following EBRT.

\section{DISCUSSION}

\section{Main findings}

The main findings of our study were: (1) a high mortality, with no significant difference between patients who received EBRT and those who were observed; (2) no clinically apparent orbital recurrences in either group; and (3) significant orbital morbidity in most patients who had been treated with EBRT.

\section{Orbital recurrence}

The reported incidence of orbital recurrence following enucleation with EOE from uveal melanoma ranges from $6-23 \% .^{5,10,12,17,18}$ Risk factors for orbital recurrence include greater intraocular tumour size, optic nerve invasion, as well as surgical transection and nonencapsulation of EOE. ${ }^{5}$ Interestingly, size of the epi-bulbar tumour nodule was not found to be a statistically significant predictor of local recurrence; however, these findings should be interpreted with the caveat that only 6 patients in this study developed orbital recurrence. ${ }^{5}$ Although we have reported a $0 \%$ local recurrence rate, both for patients who were observed 
198

199

200

201

202

203

204

205

206

207

208

209

210

211

212

213

214

215

216

217

218

219

220

221

and for those undergoing adjuvant radiotherapy, this figure should be interpreted with caution given our relatively short follow up times (median: 1.8 years; mean: 2.7 years; IQR: 3.0 years; range: $0.1-10.2$ years). However, these findings are likely representative of the realworld situation, given that many patients with EOE may not develop an orbital recurrence, to some extent because of poor life expectancy. From our data, Hanley's 'Rule of Three' formula would estimate the expected population probability of orbital recurrence in patients observed without EBRT following enucleation to be $10.3 \%$ (3/29; accepting a standard 0.05 type-1 error).${ }^{19}$ Furthermore, there is limited data in the literature to determine whether or not the development of orbital recurrence impacts survival, as some patients with orbital recurrence live for many years. ${ }^{20}$ However orbital recurrence, when it occurs, can be very difficult to manage especially when there is an orbital implant in situ, resulting in significant morbidity.

While previous studies report that most cases of orbital recurrence following enucleation occur within the first three post-operative years (mean: 2 years), ${ }^{18}$ there are some exceptional cases of orbital recurrence occurring 20-, ${ }^{21} 26-,{ }^{22} 28-,{ }^{23} 35-{ }^{20}$ and 42 -years ${ }^{24}$ following enucleation. In keeping with this, more recent reports suggest that secondary melanoma within the orbit tends to follow a bimodal distribution, with a group of patients presenting early $(<1$ year following treatment for the primary tumor) and another cohort developing orbital disease much later ( $>5$ years later $).{ }^{20}$ Treatment modalities for orbital recurrence include exenteration, surgical debulking, radiotherapy, chemotherapy or a combination thereof. ${ }^{20}$ Recently, neoadjuvant intra-arterial melphalan has been used in an effort to cytoreduce orbital recurrence of uveal melanoma prior to surgery. ${ }^{25}$

\section{Neo-adjuvant and adjuvant radiotherapy}


In 1990's, the Collaborative Ocular Melanoma Study (COMS) group investigated pre-

223

224

225 enucleation radiotherapy for large choroidal melanomas. ${ }^{26}$ In their report on long-term outcomes, they concluded that there was no survival advantage attributable to pre-operative radiotherapy and reported an overall survival of $32 \%$ at 10 -years. ${ }^{27}$ Unfortunately, this trial excluded patients with evidence of EOE $>2 \mathrm{~mm}$ detected either by ultrasonography or clinical examination, and as such, it is unclear whether or not these results can be extrapolated to patients with $\mathrm{EOE} \geq 2 \mathrm{~mm}$ undergoing enucleation.

The literature on post-enucleation radiotherapy for patients with EOE is sparse.

Adjuvant radiotherapy is often mentioned anecdotally as a means of treating presumed residual microscopic disease; however, only a handful of studies have reported outcomes of post-enucleation radiotherapy. From the authors institution, Hykin et al reported a series of 17 patients undergoing EBRT following enucleation. ${ }^{12}$ Only one of these patients developed orbital recurrence, which was diagnosed 10 weeks following enucleation and 3 weeks after completing a course of radiotherapy (consisting of 60 Gy megavoltage photons in 30 fractions). Based on this experience, in our high-volume Ocular Oncology Service, we offer EBRT to patients with a surgically visible nodule (usually $>5 \mathrm{~mm}$ ) of EOE especially when the tumour capsule is breached. EBRT is given at 3 months post-surgery to allow for surgical wound healing. Finger et al reported high-dose-rate interstitial brachytherapy of the orbit in nine patients after enucleation for UM with EOE, one of whom had a massive orbital tumour at the time of the radiotherapy. ${ }^{14}$ None of their patients developed orbital recurrence after a median of 18 months (range, 1-62). These results are in keeping with our own study, in which we did not identify any cases of orbital recurrence after either observation or EBRT.

High-dose irradiation following enucleation for UM with EOE can lead to severe socket contraction ${ }^{28}$ in approximately $40 \%$ of patients. ${ }^{13}$ Nasser et al reported the outcomes of 12 patients requiring socket reconstruction following EBRT. While reconstruction using 
oral mucous membrane grafting was successful, a significant proportion of their patients

$248(42 \% ; 5 / 12)$ died from metastatic disease shortly after their diagnosis of UM (range, 7 - 27

249 months). ${ }^{13}$

251 Survival

In our study, the actuarial 10 -year overall survival rate was only $12 \%$. Several studies have found both the presence, and size $>5 \mathrm{~mm}$ of EOE to be associated with poorer prognosis. ${ }^{7,8,29}$ Coupland et al found that EOE correlated with several histopathologic and cytogenetic features in the intraocular tumour that are known to be associated with an increased risk of metastasis, including epithelioid cellularity, closed loops, high mitotic count and monosomy $3 .^{6}$ Therefore, the presence of EOE, regardless of the extent, may merely serve as an indicator of increased underlying tumour malignancy. ${ }^{6}$ In support of this, many older studies have found the size of EOE to be prognostically irrelevant. ${ }^{5,10,12,30}$ Our extremely poor 10 -year survival outcome of $12 \%$ is in keeping with AJCC survival estimates based on the large size of intraocular tumors included in this study (mean LBD and thickness: $18.5 \pm 6.0 \mathrm{~mm}$ and $9.2 \pm 4.2 \mathrm{~mm}$, respectively) and the presence of EOE.

\section{Treatment of uveal melanoma with EOE}

While exenteration may occasionally be necessary for cases of massive $(>1,000$ $\mathrm{mm}^{3}$ ) orbital involvement from $\mathrm{UM},{ }^{31-33}$ the past four decades have seen a general shift towards more conservative management. Some cases of EOE can be successfully managed with globe-sparing modalities, including proton beam radiotherapy ${ }^{34,35}$ or plaque brachytherapy; ${ }^{36,37}$ however, enucleation is still widely performed due to significant radiation 
complications that may arise following plaque brachytherapy or proton beam therapy of large, anteriorly located tumours.

Burris et al reported a series of case from our institution where anterior EOE was detected preoperatively on slit lamp examination in $100 \%$ cases, and therefore the surgical approach was easily converted to include modified enucleation. This paper also reported that ultrasonography can miss posterior EOE especially when located at the insertion of the inferior oblique muscle. ${ }^{15}$ The incidence of surgical transection of EOE is relatively high in the reported literature. ${ }^{10,12}$ However in our series, histopathological examination of the globes rarely found the nodule of EOE to be incompletely excised with breach of the tumour capsule. This is most likely related to our meticulous surgical approach. We exercise caution if there is any suspicion of EOE, and for completion of the resection use enucleation scissors or the Foster Snare if it can be placed posteriorly enough without disturbing the EOE. If the nodule of EOE is transected, we take meticulous care at the time of surgery to ensure that all visible tumour is removed from the orbit. Similarly, if at enucleation, orbital spread is found, then meticulous orbital exploration to excise any melanoma seeds can be performed at the same operation to achieve local tumour control. We believe this to be a critical step in management of these cases, as residual viable tumour cells left behind will increase the risk of orbital recurrence.

\section{Study strengths and weaknesses}

The main strength of our study is the large size of our cohort, which to our knowledge is greater than any previously reported. The primary weakness is the short follow-up, which occurred mostly because so many of our patients had died. As a result, it is possible that some of these patients died before a local orbital relapse was detectable. Another weakness is the 
294

295

296

297

298

299

300

301

302

303

304

305

306

307

308

309

310

311

312

313

314

315

316

317

lack of randomization between observation and adjuvant EBRT with patients receiving prophylactic radiotherapy being more likely to have larger and/or incompletely excised EOE.

Additionally, although there was no statistically significant difference in the administration of prior radiotherapy (ie. plaque brachytherapy/proton beam radiotherapy) between the two groups, it is possible that some of the histopathological features were impacted by the primary treatment. As one patient present with systemic metastasis within a month of enucleation, it is possible that this orbital tumour may have been a local metastasis rather than extraocular extension directly from the tumour, as metastasis of treated choroidal melanoma to the contralateral orbit have been previously reported. ${ }^{38-40}$ Unfortunately, due to the limitations pertaining to the standardized documentation of metastatic status we were unable compare the risk of distant metastasis between the groups. Likewise, as the cause of death was not known in many patients, we could only report all-cause mortality and overall survival.

\section{Scope for further studies}

There is scope for further studies. Much of the literature surrounding the incidence of orbital recurrence in eyes undergoing enucleation for uveal melanoma with EOE is more than 30 years old,,$^{5,10,12,17,18}$ and based on a relatively small number of cases. Therefore, further research is required to determine the contemporary risk of orbital recurrence in the setting of modern-day pre-operative imaging such as MRI and modified surgical techniques. There is also scope for studies aimed at reducing radiation-induced morbidity by employing alternative delivery modalities, such as brachytherapy. ${ }^{14}$ 
319 enucleation for uveal melanoma is sparse ${ }^{12-15}$ and little has been published in the past three

320 decades with respect to the incidence of orbital recurrence following enucleation. Our

321 findings suggest that cases with relatively small EOE of less than $5 \mathrm{~mm}$ in thickness, with

322 complete excision from the orbital contents can be safely observed without the need for

323 adjuvant radiotherapy. Further multi-centred research is required to definitively determine the

324 role of EBRT in cases with more extensive EOE and in instances when the pseudo-capsule is 325 breached. 
326 TABLE and FIGURE LEGENDS:

327 Table 1. Demographics, intraocular tumour features and laboratory findings of patients

328 undergoing external beam radiotherapy compared to those who were observed.

329

330 Figure 1. Kaplan Meier curve demonstrating all-cause mortality for the entire cohort

332 Figure 2. Kaplan Meier curve demonstrating all-cause mortality stratified by whether or not 333 external beam radiotherapy was administered. 


\section{REFERENCES:}

1. Avery RB, Diener-West M, Reynolds SM, Grossniklaus HE, Green WR, Albert DM. Histopathologic characteristics of choroidal melanoma in eyes enucleated after iodine 125 brachytherapy in the collaborative ocular melanoma study. Arch Ophthalmol. 2008;126(2):207-212.

2. Shields $\mathrm{CL}$, Furuta $\mathrm{M}$, Thangappan $\mathrm{A}$, et al. Metastasis of uveal melanoma millimeterby-millimeter in 8033 consecutive eyes. Arch Ophthalmol. 2009;127(8):989-998.

3. Bellmann C, Lumbroso-Le Rouic L, Levy C, et al. Uveal melanoma: management and outcome of patients with extraocular spread. Br J Ophthalmol. 2010;94(5):569-574.

4. Shields CL, Kaliki S, Furuta M, Fulco E, Alarcon C, Shields JA. American Joint Committee on Cancer Classification of Uveal Melanoma (Anatomic Stage) Predicts Prognosis in 7,731 Patients: The 2013 Zimmerman Lecture. Ophthalmology. 2015;122(6):1180-1186.

5. Affeldt JC, Minckler DS, Azen SP, Yeh L. Prognosis in uveal melanoma with extrascleral extension. Arch Ophthalmol. 1980;98(11):1975-1979.

6. Coupland SE, Campbell I, Damato B. Routes of extraocular extension of uveal melanoma: risk factors and influence on survival probability. Ophthalmology. 2008;115(10):1778-1785.

7. van Beek JG, Koopmans AE, Vaarwater J, et al. The prognostic value of extraocular extension in relation to monosomy 3 and gain of chromosome $8 q$ in uveal melanoma. Invest Ophthalmol Vis Sci. 2014;55(3):1284-1291.

8. Kujala E, Damato B, Coupland SE, et al. Staging of ciliary body and choroidal melanomas based on anatomic extent. J Clin Oncol. 2013;31(22):2825-2831.

9. Hogan M. Clinical aspects, management and prognosis of melanomas of the uvea and optic nerve. In: Boniuk M, ed. Ocular and Adnexal Tumors, New and Controversial Aspects. St Louis: Mosby; 1964:280.

10. Shammas HF, Blodi FC. Orbital extension of Choroidal and ciliary body melanomas. Arch Ophthalmol. 1977;95(11):2002-2005.

11. Kersten RC, Tse DT, Anderson RL, Blodi FC. The role of orbital exenteration in choroidal melanoma with extrascleral extension. Ophthalmology. 1985;92(3):436443.

12. Hykin PG, McCartney AC, Plowman PN, Hungerford JL. Postenucleation orbital radiotherapy for the treatment of malignant melanoma of the choroid with extrascleral extension. Br J Ophthalmol. 1990;74(1):36-39.

13. Nasser QJ, Gombos DS, Williams MD, et al. Management of radiation-induced severe anophthalmic socket contracture in patients with uveal melanoma. Ophthalmic Plast Reconstr Surg. 2012;28(3):208-212.

14. Finger PT, Tena LB, Semenova E, Aridgides P, Choi WH. Extrascleral extension of choroidal melanoma: post-enucleation high-dose-rate interstitial brachytherapy of the orbit. Brachytherapy. 2014;13(3):275-280.

15. Burris $\mathrm{CKH}$, Papastefanou VP, Thaung $\mathrm{C}$, et al. Detection of extrascleral extension in uveal melanoma with histopathological correlation. Orbit. 2018;37(4):287-292.

16. Dogrusoz M, Kroes WG, van Duinen SG, et al. Radiation Treatment Affects Chromosome Testing in Uveal Melanoma. Invest Ophthalmol Vis Sci. 2015;56(10):5956-5964. 
400

401

402

403

404

405

406

407

408

409

410

411

412

413

414

415

416

417

418

419

420

421

422

423

424

425

426

427

428

429

430

17. Pach JM, Robertson DM, Taney BS, Martin JA, Campbell RJ, O'Brien PC. Prognostic factors in choroidal and ciliary body melanomas with extrascleral extension. Am J Ophthalmol. 1986;101(3):325-331.

18. Jensen OA. Malignant melanomas of the human uvea: 25-year follow-up of cases in Denmark, 1943--1952. Acta Ophthalmol (Copenh). 1982;60(2):161-182.

19. Hanley JA, Lippman-Hand A. If nothing goes wrong, is everything all right? Interpreting zero numerators. JAMA. 1983;249(13):1743-1745.

20. Rose AM, Cowen S, Jayasena CN, Verity DH, Rose GE. Presentation, Treatment, and Prognosis of Secondary Melanoma within the Orbit. Front Oncol. 2017;7:125.

21. Shields JA, Augsburger JJ, Dougherty MJ. Orbital recurrence of choroidal melanoma 20 years after enucleation. Am J Ophthalmol. 1984;97(6):767-770.

22. Russo A, Rene C, Coupland SE, Sagili S, Damato B. Discrepancy between fluorescence in situ hybridization and multiplex ligation-dependent probe amplification in orbital recurrence of uveal melanoma 26 years after enucleation. Ophthalmic Plast Reconstr Surg. 2012;28(6):e140-142.

23. Allen JC, Jaeschke WH. Recurrence of malignant melanoma in an orbit after 28 years. Arch Ophthalmol. 1966;76(1):79-81.

24. Shields JA, Augsburger JJ, Donoso LA, Bernardino VB, Jr., Portenar M. Hepatic metastasis and orbital recurrence of uveal melanoma after 42 years. Am J Ophthalmol. 1985;100(5):666-668.

25. Francis JH, Barker CA, Yin VT, et al. Chemoreduction of Orbital Recurrence of Uveal Melanoma by Intra-Arterial Melphalan. Ocul Oncol Pathol. 2019;5(3):186-189.

26. The Collaborative Ocular Melanoma Study (COMS) randomized trial of preenucleation radiation of large choroidal melanoma II: initial mortality findings. COMS report no. 10. Am J Ophthalmol. 1998;125(6):779-796.

27. Hawkins BS, Collaborative Ocular Melanoma Study G. The Collaborative Ocular Melanoma Study (COMS) randomized trial of pre-enucleation radiation of large choroidal melanoma: IV. Ten-year mortality findings and prognostic factors. COMS report number 24. Am J Ophthalmol. 2004;138(6):936-951.

28. Lederman M. Radiotherapy in the treatment of orbital tumours. Br J Ophthalmol. 1956;40(10):592-610.

29. Kivelä T, Simpson E, Grossniklaus H. Uveal melanoma. 8th ed. New York, NY: Springer; 2017.

30. Kidd MN, Lyness RW, Patterson CC, Johnston PB, Archer DB. Prognostic factors in malignant melanoma of the choroid: a retrospective survey of cases occurring in Northern Ireland between 1965 and 1980. Trans Ophthalmol Soc U K. 1986;105 ( Pt 1):114-121.

31. Shields JA, Shields CL. Massive orbital extension of posterior uveal melanomas. Ophthalmic Plast Reconstr Surg. 1991;7(4):238-251.

32. Ross JJ, Dean SJ, Koppel DA, Roberts F, Kemp EG. Massive orbital recurrence of uveal melanoma without metastases after 28 years. Br J Ophthalmol. 2010;94(5):632.

33. Shields CL, Shields JA, Yarian DL, Augsburger JJ. Intracranial extension of choroidal melanoma via the optic nerve. Br J Ophthalmol. 1987;71(3):172-176.

34. Seibel I, Riechardt Al, Erb-Eigner K, et al. Proton Beam Irradiation: A Safe Procedure in Postequatorial Extraocular Extension From Uveal Melanoma. Am J Ophthalmol. 2018;191:49-53. 
35. Weissgold DJ, Gragoudas ES, Green JP, Kent CJ, Rubin PA. Eye-sparing treatment of massive extrascleral extension of choroidal melanoma. Arch Ophthalmol. 1998;116(4):531-533.

36. Augsburger JJ, Schneider S, Narayana A, et al. Plaque radiotherapy for choroidal and ciliochoroidal melanomas with limited nodular extrascleral extension. Can J Ophthalmol. 2004;39(4):380-387.

37. Semenova E, Finger PT. Palladium-103 plaque radiation therapy for American Joint Committee on cancer T3- and T4-staged choroidal melanomas. JAMA Ophthalmol. 2014;132(2):205-213.

38. George S, Cooke CA, Mc Ginnity GF, White S, Venkatraman L. Treated choroidal melanoma with late metastases to the contralateral orbit. Clin Med Pathol. 2009;2:58.

39. Bohm MR, Tsianakas A, Merte RL, et al. Mutational analysis of GNAQ and GNA11 to aid therapy management of a choroidal melanoma metastatic to the contralateral orbit. JAMA Ophthalmol. 2013;131(6):812-814.

40. McElnea E, Stevenson LJ, La Rosa CS, Liew S, Hardy TG. Choroidal Melanoma Metastatic to the Contralateral Medial Rectus After Orbital Exenteration. Turk J Ophthalmol. 2019;49(5):305-309. 
451 Table 1. Demographics, intraocular tumour features and laboratory findings of patients

452 undergoing external beam radiotherapy compared to those who were observed.

\begin{tabular}{|c|c|c|c|}
\hline & $\begin{array}{c}\text { Observation } \\
\mathbf{n}=\mathbf{2 9}\end{array}$ & $\begin{array}{l}\text { EBRT } \\
\mathrm{n}=\mathbf{2 2}\end{array}$ & p-value \\
\hline Age* $^{*}($ mean \pm SD) years & $69 \pm 14$ & $65 \pm 16$ & 0.334 \\
\hline LBD* (mm) & $18.7 \pm 5.7$ & $18.2 \pm 6.5$ & 0.779 \\
\hline Thickness* (mm) & $9.7 \pm 4.6$ & $8.5 \pm 3.6$ & 0.374 \\
\hline & \multicolumn{2}{|c|}{$n=12$} & \\
\hline Prior radiotherapy $^{\dagger}$ & $8(67)$ & $4(33)$ & 0.518 \\
\hline Size $\operatorname{EOE}^{\ddagger}($ mean, median, range) $(\mathrm{mm})$ & $\begin{array}{c}n=18 \\
2.9,2.6,0.5-6.0\end{array}$ & $\begin{array}{c}n=18 \\
5.6,5.1,1.5-12.0\end{array}$ & 0.008 \\
\hline Closed Loops $^{\dagger}(\%)$ & $\begin{array}{c}n=24 \\
10(42)\end{array}$ & $\begin{array}{c}n=19 \\
10(53)\end{array}$ & 0.547 \\
\hline $\begin{array}{l}\text { Cell Type }^{* *} \\
\text { Spindle (\%) } \\
\text { Mixed (\%) } \\
\text { Epithelioid (\%) }\end{array}$ & $\begin{array}{c}n=24 \\
7(29) \\
10(42) \\
7(29)\end{array}$ & $\begin{array}{c}n=21 \\
9(43) \\
10(48) \\
2(10)\end{array}$ & 0.244 \\
\hline Mitotic count ${ }^{*}($ mean \pm SD) & $\begin{array}{c}n=22 \\
2.5 \pm 2.2\end{array}$ & $\begin{array}{c}n=20 \\
2.7 \pm 2.0\end{array}$ & 0.731 \\
\hline Complete surgical excision of $\mathrm{EOE}^{\dagger}$ & $\begin{array}{c}n=25 \\
14(56)\end{array}$ & $\begin{array}{l}n=20 \\
2(10)\end{array}$ & 0.002 \\
\hline EOE pseudo-encapsulated ${ }^{\dagger}$ & $\begin{array}{l}n=21 \\
7(33)\end{array}$ & $\begin{array}{l}n=14 \\
3(21)\end{array}$ & 0.704 \\
\hline Monosomy $3^{\dagger}$ & $\begin{array}{c}n=14 \\
11(79)\end{array}$ & $\begin{array}{l}n=11 \\
5(45)\end{array}$ & 0.098 \\
\hline $8 q$ gain $^{\dagger}$ & $\begin{array}{c}n=11 \\
11(100)\end{array}$ & $\begin{array}{l}n=11 \\
9(82)\end{array}$ & 0.238 \\
\hline
\end{tabular}

453

454

455

456

457

458

459

460

461

462

463

LBD: Largest basal diameter

EOE: Extraocular extension

* Students t-test (continuous variables that are normally distributed)

* Mann-Whitney U (continuous variables that are not normally distributed)

$\dagger$ Fishers Exact test (categorical variables)

** Chi-square test

Mitotic count is per high power field 
464 Figure 1. Kaplan Meier curve demonstrating all-cause mortality for the entire cohort

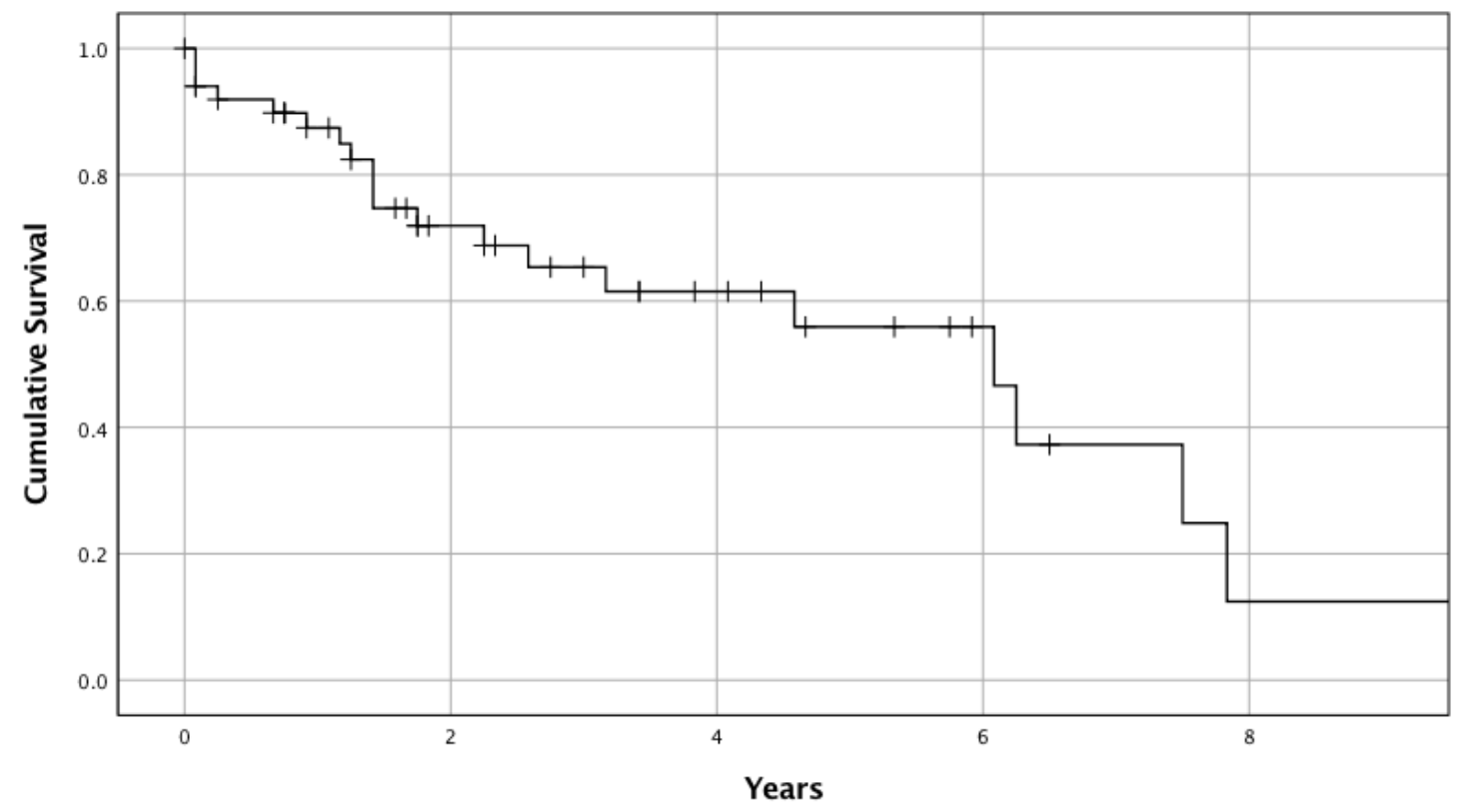

Numbers at risk

51

24

15

9

4

465

466 
467 Figure 2. Kaplan Meier curve demonstrating all-cause mortality stratified by whether or not 468 external beam radiotherapy was administered.

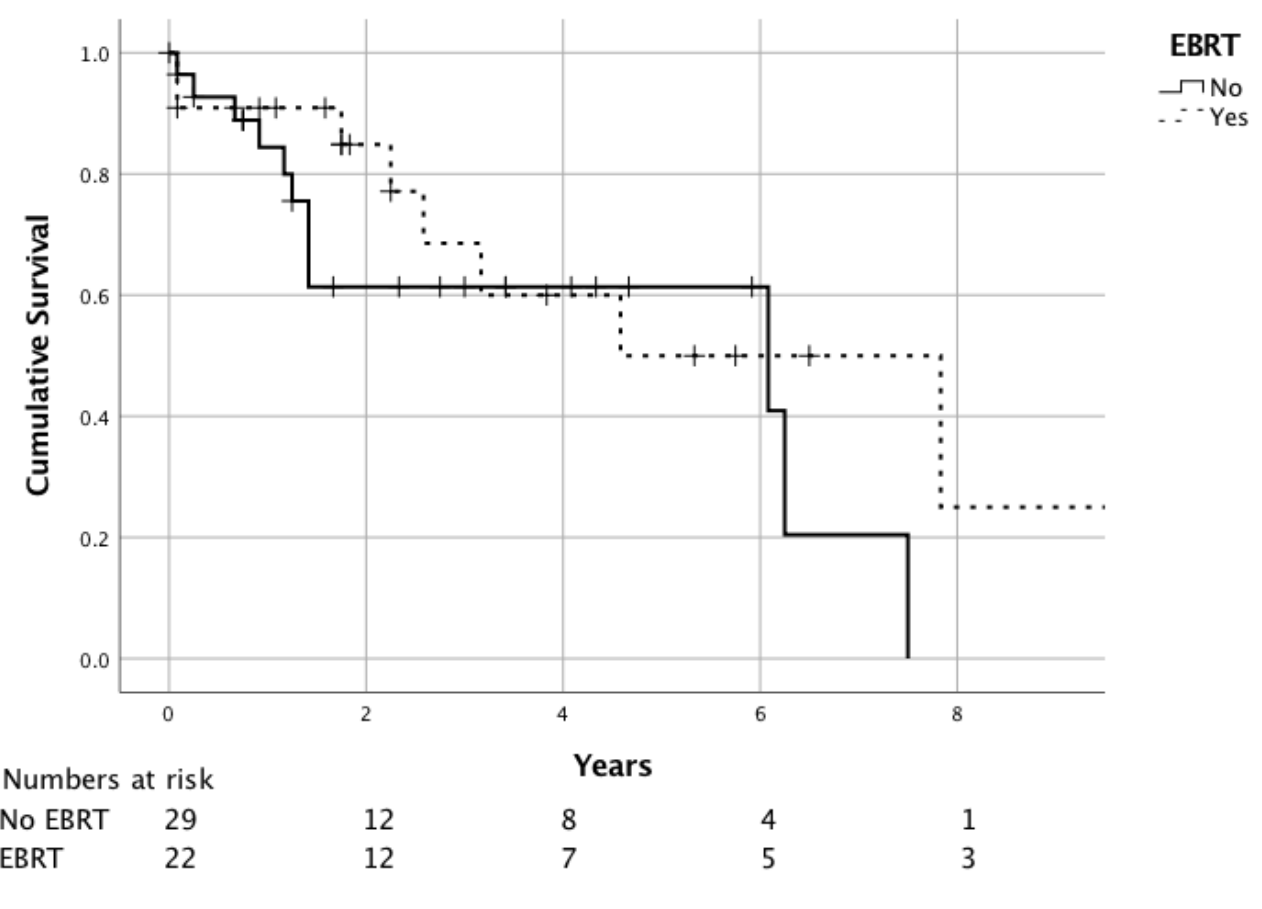

